\title{
Circulating miR-18a in plasma contributes to cancer detection and monitoring in patients with gastric cancer
}

\author{
Masahiro Tsujiura Shuhei Komatsu • Daisuke Ichikawa • Atsushi Shiozaki $\cdot$ Hirotaka Konishi · \\ Hiroki Takeshita $\cdot$ Ryo Moriumura $\cdot$ Hiroaki Nagata $\cdot$ Tsutomu Kawaguchi - Shoji Hirajima • \\ Tomohiro Arita $\cdot$ Hitoshi Fujiwara $\cdot$ Kazuma Okamoto $\cdot$ Eigo Otsuji
}

Received: 15 December 2013/Accepted: 23 February 2014/Published online: 14 March 2014

(C) The International Gastric Cancer Association and The Japanese Gastric Cancer Association 2014

\begin{abstract}
Background Recently, circulating microRNAs have been reported to be stably detectable in plasma/serum and to function as potent non-invasive biomarkers in various cancers. We hypothesized that miR-18a could contribute to a novel plasma biomarker in patients with gastric cancer (GC).

Methods We focused on miR-18a, which is a component of miR-17-92 cluster and has been reported as highly expressed in GC tissues. The study involved three steps: (1) confirmation of the higher miR-18a expression in primary GC tissues and GC cell lines than in normal gastric tissues and a fibroblast cell line; (2) evaluation of the plasma miR18 a assay using quantitative RT-PCR by comparing 104 GC patients and 65 healthy volunteers; (3) evaluation of monitoring tumor dynamics by the plasma miR-18a assay. Results (1) The miR-18a expressions were significantly higher in GC tissues than in normal gastric tissues $(P=0.0286)$ and higher in all examined GC cell lines than in the fibroblast cell line. (2) The plasma miR-18a concentrations were significantly higher in GC patients than in healthy controls $(P<0.0001)$. The value of the area under
\end{abstract}

M. Tsujiura and S. Komatsu contributed equally to this work.

Electronic supplementary material The online version of this article (doi:10.1007/s10120-014-0363-1) contains supplementary material, which is available to authorized users.

M. Tsujiura · S. Komatsu ( $₫) \cdot$ D. Ichikawa · A. Shiozaki

H. Konishi · H. Takeshita - R. Moriumura - H. Nagata ·

T. Kawaguchi $\cdot$ S. Hirajima $\cdot$ T. Arita $\cdot$ H. Fujiwara .

K. Okamoto $\cdot$ E. Otsuji

Division of Digestive Surgery, Department of Surgery,

Kyoto Prefectural University of Medicine, 465 Kajii-cho,

Kawaramachihirokoji, Kamigyo-ku, Kyoto 602-8566, Japan

e-mail: skomatsu@koto.kpu-m.ac.jp the receiver-operating characteristic curve was 0.8059. (3) The plasma miR-18a levels were significantly reduced in postoperative samples compared to in preoperative samples $(P=0.0002)$. In an miR-18a overexpressing cell line, the miR-18a concentration of cultured medium increased in both cell number and time-course dependent manners, suggesting microRNA might be released from cancer cells into the surrounding environment.

Conclusions Circulating miR-18a could be a useful biomarker for screening GC and monitoring tumor dynamics.

Keywords Biomarker - Circulating nucleic acids . Gastric cancer · microRNA · Plasma

\section{Introduction}

Gastric cancer (GC) is the fourth most common cancer and the second leading cause of cancer-related death in the world [1]. Although recent improvements in diagnostic techniques and perioperative management have resulted in an increase in the early detection of GC and a decrease in its mortality in the past decades, a total of 986,600 new GC cases and 738,000 deaths are estimated to have occurred in 2008 worldwide [1]. In particular, advanced-stage patients still demonstrate extremely poor survival rates [2]. Thus, the primary tumors must be detected at an early stage, and recurrent disease must be diagnosed when it is still minimal or clinically occult in order to improve the clinical outcome of patients with GC.

Recent gene expression studies identified some genes that are differentially expressed in GC [3, 4]. In the clinical setting, however, few molecules have been assayed as therapeutic and/or diagnostic biomarkers. Conventional serum tumor markers, such as carcinoembryonic antigen 
(CEA) and carbohydrate antigen 19-9 (CA19-9), have been used as diagnostic assays to monitor GC [5]. However, these markers lack sufficient sensitivity and specificity to facilitate early detection. Therefore, the significance of novel biomarkers using a non-invasive diagnostic assay for GC should be emphasized.

MicroRNAs (miRNAs) are a group of noncoding small RNAs that are involved in post-translational regulation of gene expression by inhibiting the stability and translation of mRNAs [6]. Recent studies have demonstrated that aberrant expressions of specific miRNAs are involved in a large variety of human malignancies, and some miRNAs have been proven to have critical roles, including both oncogenic and tumor-suppressive functions [7, 8].

Circulating miRNAs have been reported to be stably detectable in plasma/serum $[9,10]$ and to exhibit resistance to endogenous ribonuclease activity by binding certain proteins such as Argonaute2 and high-density lipoproteins [11-13], or being packed by some kinds of secretory particles including apoptotic bodies and exosomes [14, 15]. Furthermore, secretory vesicles including miRNAs have been shown to be able to function as intercellular transmitters [14-16], suggesting that circulating miRNAs in plasma/serum possess various roles in cancer development and metastasis. Based on these findings, the detection of circulating miRNAs seems to have a high potency as a reproducible and reliable biomarker as well as a therapeutic target; thus, it is considered to be extremely meaningful to elucidate their biological and oncogenic characteristics and to establish a novel miRNA-related biomarker for cancer patients.

In this study, we focused on the miR-17-92 cluster, which is located at chromosome $13 \mathrm{q} 31$ and consists of seven miRNAs: miR-17-5p, miR-17-3p, miR-18a, miR19a, miR-19b, miR-20a and miR-92a. This cluster was reported to possess potential oncogenic function in various malignant diseases including GC [17, 18]. Some reports have shown new perceptions of the relationship between miR-17-92 cluster's malignant potential and biogenesis or transcriptional mechanism [19-22]. These findings strongly urged us to execute further investigation under the assumption that plasma miRNAs located in the miR-17-92 cluster could potentially be useful biomarkers in patients with GC.

Previous reports have shown the overexpression of the miR-17-92 cluster in GC tissues compared with normal gastric tissues [23-29]. According to these reports, miR$18 \mathrm{a}$ was one of the most highly expressed and frequently upregulated miRNAs in GC tissues. Therefore, we selected miR-18a as a candidate for this plasma assay. MiR-18a also has been reported to show altered expression in various malignant diseases [30, 31]. In breast cancer, the relationship with ERalpha, identified as a direct target of miR- 18a, has been elucidated. MiR-18a represses ERalpha translation directly by binding to its mRNA at the $3^{\prime}$ untranslated region [32, 33]. Conversely, ERalpha also binds to c-MYC and in turn upregulates the expression of pre-miR-18a in an estrogen-dependent manner [34]. In nasopharyngeal carcinoma, miR-18a was reported to negatively regulate Dicer1 expression and promote the growth, migration and invasion of nasopharyngeal cancer cells, which consequently causes the global downregulation of miRNA expression levels [35].

In the present study, we investigated whether the circulating miR-18a in plasma could screen cancer patients by comparing findings in GC patients and healthy controls, and monitor tumor dynamics of GC. Consequently, we clearly demonstrated its potential usefulness. Our data provided evidence that the plasma miR-18a could discriminate GC patients from healthy controls with a clinically satisfactory degree of sensitivity and specificity.

\section{Methods}

\section{Patients and samples}

The study was approved by the ethics committee at Kyoto Prefectural University of Medicine, and each subject provided signed informed consent. Between September 2008 and August 2010, preoperative plasma samples were collected from 104 GC patients as well as 65 healthy volunteers. The patients' characteristics with respect to age, sex, histopathology and stages of disease are described in Table 1 . None of the patients had received chemotherapy or radiotherapy before blood sampling. The volunteers were medical personnel and patients with a benign disease such as cholelithiasis. Paired plasma samples were collected from 22 patients before and 1 month after curative gastrectomy, and findings in pre- and postoperative plasma samples were compared. Blood samples were centrifuged by the following protocol $(1,500 \mathrm{rpm}$ for $30 \mathrm{~min}$, $3,000 \mathrm{rpm}$ for $5 \mathrm{~min}$ and 4,500 rpm for $5 \mathrm{~min}$ ) to prevent contamination by cellular nucleic acids and stored at $-80{ }^{\circ} \mathrm{C}$ until further processing.

Formalin-fixed paraffin-embedded tissue samples were collected from 21 patients to compare miRNA expressions between primary tumor lesions and adjacent non-tumorous lesions. Macroscopic and microscopic classifications of tumors were based on the UICC/TMN staging system [36].

GC cell lines and human fibroblast cell line

Six human GC cell lines, MKN28, MKN45, MKN74, NUGC-4, HGC-27 and Kato III, and one human fibroblast cell line, WI-38, were used in this study and obtained from 
Table 1 Association of plasma miR-18a concentrations with clinicopathological factors in 104 GC patients

\begin{tabular}{llll}
\hline Variable & $\begin{array}{l}\text { Patients } \\
(N=104)\end{array}$ & $\begin{array}{l}\text { Plasma } \\
\text { miR-18a } \\
\text { concentration } \\
(\text { amol/ } \mu \mathrm{l})\end{array}$ & $P$ value* \\
& & \\
\hline
\end{tabular}

\begin{tabular}{|c|c|c|c|}
\hline \multicolumn{4}{|l|}{ Age (years) } \\
\hline Mean (range) & $65.6(38-94)$ & & \multirow{3}{*}{0.7564} \\
\hline Under 65 & $43(41 \%)$ & 9.731 & \\
\hline 65 or more & $61(59 \%)$ & 7.777 & \\
\hline \multicolumn{4}{|l|}{ Sex } \\
\hline Male & $67(64 \%)$ & 7.611 & \multirow[t]{2}{*}{0.6106} \\
\hline Female & $37(36 \%)$ & 10.350 & \\
\hline \multicolumn{4}{|l|}{ Tumor size } \\
\hline Mean (range) & $44.7(5-185)$ & & \multirow{3}{*}{0.4949} \\
\hline Under $45 \mathrm{~mm}$ & $70(67 \%)$ & 9.099 & \\
\hline $45 \mathrm{~mm}$ or more & $34(33 \%)$ & 7.526 & \\
\hline \multicolumn{4}{|l|}{ Histopathology } \\
\hline $\begin{array}{l}\text { Differentiated } \\
\quad \text { (tub1/tub2/pap) }\end{array}$ & $48(46 \%)$ & 9.852 & \multirow[t]{2}{*}{0.6225} \\
\hline $\begin{array}{l}\text { Undifferentiated } \\
\text { (por/sig/muc) }\end{array}$ & $56(54 \%)$ & 7.499 & \\
\hline \multicolumn{4}{|l|}{ Lymphatic invasion } \\
\hline ly0 & $57(55 \%)$ & 9.662 & \multirow[t]{2}{*}{0.2112} \\
\hline ly1/ly2/ly3 & $47(45 \%)$ & 7.279 & \\
\hline \multicolumn{4}{|l|}{ Venous invasion } \\
\hline v0 & $71(68 \%)$ & 8.191 & \multirow[t]{2}{*}{0.8559} \\
\hline $\mathrm{v} 1 / \mathrm{v} 2 / \mathrm{v} 3$ & $33(32 \%)$ & 9.433 & \\
\hline \multicolumn{4}{|l|}{ T-stage ${ }^{\mathrm{a}}$} \\
\hline $\mathrm{T} 1$ & $61(59 \%)$ & 9.320 & \multirow[t]{4}{*}{0.4099} \\
\hline $\mathrm{T} 2$ & $9(9 \%)$ & 10.021 & \\
\hline $\mathrm{T} 3$ & $13(12 \%)$ & 6.252 & \\
\hline $\mathrm{T} 4$ & $21(20 \%)$ & 7.278 & \\
\hline \multicolumn{4}{|l|}{$\mathrm{N}$-stage ${ }^{a}$} \\
\hline No & $63(61 \%)$ & 9.500 & \multirow[t]{2}{*}{0.2111} \\
\hline $\mathrm{N} 1 / \mathrm{N} 2 / \mathrm{N} 3$ & $41(39 \%)$ & 7.179 & \\
\hline \multicolumn{4}{|l|}{ M-stage ${ }^{a}$} \\
\hline M0 & $95(91 \%)$ & 8.826 & \multirow[t]{2}{*}{0.7549} \\
\hline M1 & $9(9 \%)$ & 6.047 & \\
\hline \multicolumn{4}{|l|}{ Stage $^{\mathrm{a}}$} \\
\hline I & $66(64 \%)$ & 9.378 & \multirow[t]{4}{*}{0.6065} \\
\hline II & $14(13 \%)$ & 6.903 & \\
\hline III & $15(14 \%)$ & 8.190 & \\
\hline IV & $9(9 \%)$ & 6.047 & \\
\hline \multicolumn{4}{|c|}{ Postoperative recurrence ${ }^{\mathrm{b}}$} \\
\hline Positive & $14(13 \%)$ & 5.727 & \multirow[t]{2}{*}{0.6328} \\
\hline Negative & $90(87 \%)$ & 9.029 & \\
\hline
\end{tabular}

a TNM classification

b Recurrence was defined as when the occurrence of cancer was confirmed by imaging modalities such as CT or PET during a regular postoperative follow-up of patients

*Mann-Whitney $U$ test and Kruskal-Wallis $H$ test were performed to compare the plasma miRNA concentration the RIKEN Cell Bank (Tsukuba, Japan). MKN28, MKN45, MKN74, NUGC-4 and Kato III were cultured in Roswell Park Memorial Institute (RPMI)-1640 (Wako, Osaka, Japan) supplemented with $10 \% \mathrm{v} / \mathrm{v}$ fetal bovine serum (FBS; Trace Scientific, Melbourne, Australia), the others in Minimum Essential Medium Alpha Modification (MEM $\alpha$; Wako, Osaka, Japan) supplemented with $10 \%$ v/v FBS. All the cell lines were incubated at $37^{\circ} \mathrm{C}$ in a humidified atmosphere containing $5 \%$ carbon dioxide.

\section{RNA extraction}

Total RNA was extracted from 100,000 cultured cells and $400 \mu \mathrm{l}$ of plasma or medium samples using mirVana PARIS Kit (Ambion, Austin, TX, USA) and finally eluted into $100 \mu \mathrm{l}$ of pre-heated $\left(95^{\circ} \mathrm{C}\right)$ elution solution according to the manufacturer's protocol. As for formalin-fixed paraffin-embedded tissues, total RNA was extracted from four slices of $15 \mu \mathrm{m}$ thickness (total $60 \mu \mathrm{m}$ ) using RecoverAll Total Nucleic Acid Isolation Kit (Ambion, Austin, TX, USA) and finally eluted into $60 \mu \mathrm{l}$ of elution solution according to the manufacturer's protocol.

\section{Protocols for the detection of miRNAs}

Reverse transcription reaction was conducted with TaqMan MicroRNA Reverse Transcription Kit (Applied Biosystems, Foster City, CA, USA), and the levels of miRNAs were quantified in duplicate by quantitative RT-PCR (qRTPCR) using the human TaqMan MicroRNA Assay Kit (Applied Biosystems, Foster City, CA, USA) as described previously [37-39]. The miRNA levels in plasma and medium were calculated using the concentration on a standard curve constructed using synthetic miRNAs, mirVana miRNA Reference Panel (Ambion, Austin, Texas, USA), because the stable and suitable PCR controls of those sample had not been reported [40]. The miRNA levels of tissues and cells were normalized using the comparative $\mathrm{Ct}$ method relative to U6 small nuclear RNA (RNU6B), and the change in expression was calculated with the equation $2^{-\Delta \Delta \mathrm{Ct}}$ [41].

Statistical analysis

The Mann-Whitney $U$ test and Kruskal-Wallis test were used to compare the miRNA concentrations of plasma and medium, and the miRNA ratio. The Wilcoxon signed-rank test was used to compare the paired GC and non-cancerous tissues and the paired plasma samples before and after gastrectomy. The Spearman rank-correlation coefficient was used to examine the relationship between the miRNA concentration and the cell number. $P$ value $<0.05$ was considered significant. Receiver-operating characteristic 
a

\begin{tabular}{|c|}
\hline $\begin{array}{l}\text { Confirmation of the higher miR-18a expression } \\
\text { in gastric cancer }\end{array}$ \\
\hline $\begin{array}{l}\text { Comparison of the miR-18a expression between } \\
\text { primary gastric cancer tissues and normal gastric } \\
\text { tissues }\end{array}$ \\
\hline $\begin{array}{l}\text { Comparison of the miR-18a expression between } \\
\text { gastric cancer cell lines and a fibroblast cell line }\end{array}$ \\
\hline $\begin{array}{l}\text { Evaluation of the plasma miR-18a expression by } \\
\text { comparing } 104 \text { gastric cancer patients with } 65 \\
\text { healthy volunteers }\end{array}$ \\
\hline $\begin{array}{l}\text { Plasma miR-18a expression analysis by } \\
\text { quantitative RT-PCR }\end{array}$ \\
\hline $\begin{array}{l}\text { Evaluation of whether plasma miR-18a expression } \\
\text { could monitor tumor dynamics }\end{array}$ \\
\hline $\begin{array}{l}\text { Comparison of miR-18a levels in paired pre- and } \\
\text { post-operative plasma in cancer patients who } \\
\text { underwent curative gastrectomy }\end{array}$ \\
\hline $\begin{array}{l}\text { Cultured medium miR-18a expression analysis by } \\
\text { real- time quantitative RT-PCR }\end{array}$ \\
\hline
\end{tabular}

Plasma miR-18a is a novel candidate as a diagnostic and monitoring marker for gastric cancer

Fig. 1 a Study design used to develop a novel biomarker of the plasma miRNA. b The expression levels of miR-18a in gastric cancer (GC) tissues compared with those in paired normal gastric tissues. The expression level of miR-18a was higher in GC tissues than in

(ROC) curves and the area under the ROC curve (AUC) were used to assess the feasibility of using the plasma miRNA concentration as a diagnostic tool for detecting GC. Statistical analyses were conducted using JMP ${ }^{\circledR} 10$ (SAS Institute Inc., Cary, NC, USA).

\section{Results}

Study design to develop a novel biomarker of the plasma miRNA

Prior to this study, we reviewed previous reports regarding miR-18a expression, including other miRNAs of the miR17-92 cluster in GC tissues compared to normal tissues (Supplementary Table S1) [23-29]. Among seven miRNAs in the miR-17-92 cluster, miR-17-5p and miR-18a were found to be the most highly expressed and frequently upregulated miRNAs according to those reports. We have already reported the usefulness of evaluating miR-17-5p b
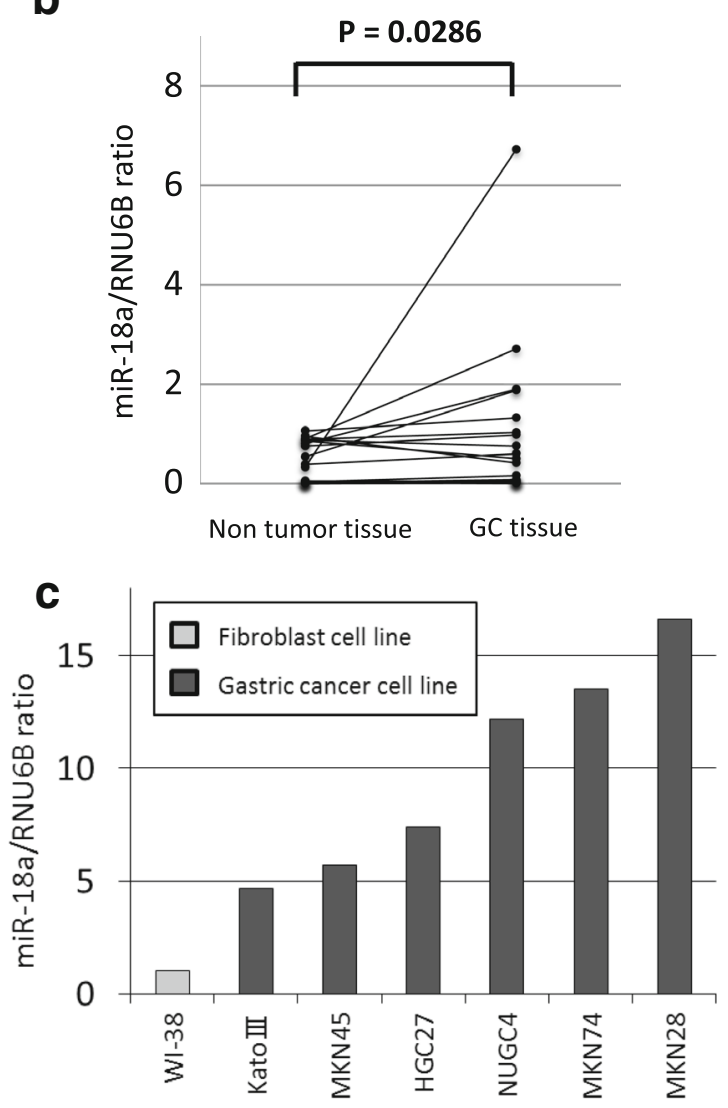

normal gastric tissues ( $P=0.0286$, Wilcoxon signed-rank test). c The expression levels of miR-18a in all examined GC cell lines were higher compared to the fibroblast cell line

levels in the plasma of GC patients [37]; therefore, we selected miR-18a as a candidate for this study.

As summarized in Fig. 1a, this study was divided into three steps: (1) confirmation of the higher miR-18a expression in primary GC tissues and GC cell lines than in normal gastric tissues and a human fibroblast cell line; (2) evaluation of the plasma miR-18a assay using qRT-PCR by comparing results from $104 \mathrm{GC}$ patients and 65 healthy volunteers; (3) evaluation of monitoring tumor dynamics by the plasma miR-18a assay in patients with GC.

MiR-18a in primary GC tissues and GC cell lines

To confirm previously reported high miR-18a expression in primary GC, we investigated its expressions in 21 paired GC tissues and adjacent non-cancerous tissues by qRTPCR. Also, the expressions of miR-18a in six human GC cell lines, MKN28, MKN45, MKN74, NUGC-4, HGC-27 and Kato III, and a human fibroblast cell line, WI-38, were evaluated by qRT-PCR. Results are shown after 


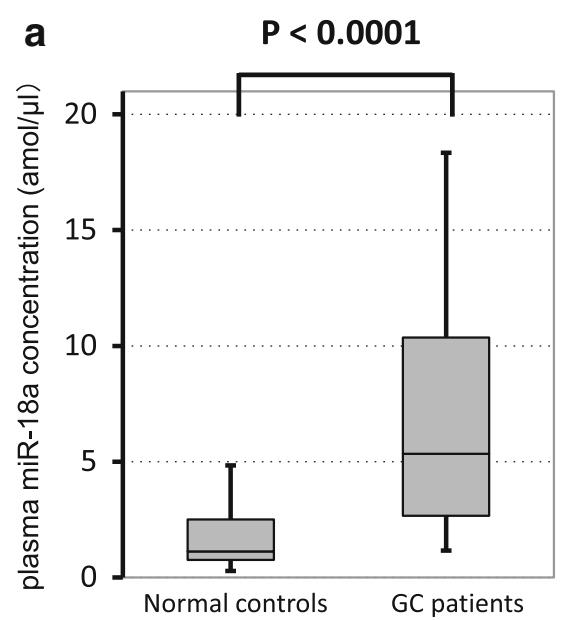

Fig. 2 a The plasma concentrations of miR-18a were significantly higher in GC patients than in normal controls $(P<0.0001$, MannWhitney $U$ test). The upper and lower limits of the boxes and the lines inside the boxes indicate the 75th and 25th percentiles and the

normalization to RNU6B expression. The miR-18a expressions were significantly higher in GC tissues than in normal gastric tissues $(P=0.0286$; Fig. 1 b) and higher in all examined GC cell lines than in the fibroblast cell line (Fig. 1c).

Evaluation of the plasma miR-18a expression using qRT-PCR in GC patients

Next, we hypothesized that the higher miR-18a expressions in primary GC tissues would influence the miR-18a expressions in plasma of GC patients. The plasma miR-18a concentrations were significantly higher in GC patients than in controls $(P<0.0001$; Fig. 2a). Representation of the data using a ROC plot showed a strong separation between the two groups, with an AUC of 0.8059 (Fig. 2b). In this model, an optimal cutoff point was indicated at $1.992 \mathrm{amol} / \mu \mathrm{l}$ with a sensitivity of 0.846 and a specificity of 0.692. Moreover, we examined the association of plasma miR-18a concentrations with clinicopathological factors in GC patients; however, no significant correlations were observed (Table 1).

Evaluation of monitoring tumor dynamics using plasma miR-18a assay in patients with GC

The plasma miR-18a concentration was analyzed in paired pre- and postoperative samples from 22 GC patients who underwent curative gastrectomy. When gastrectomy was performed, in other words, primary cancer tissues were resected; the plasma miR-18a levels were found to be significantly reduced postoperatively $(P=0.0002 ;$ Fig. 3$)$. b

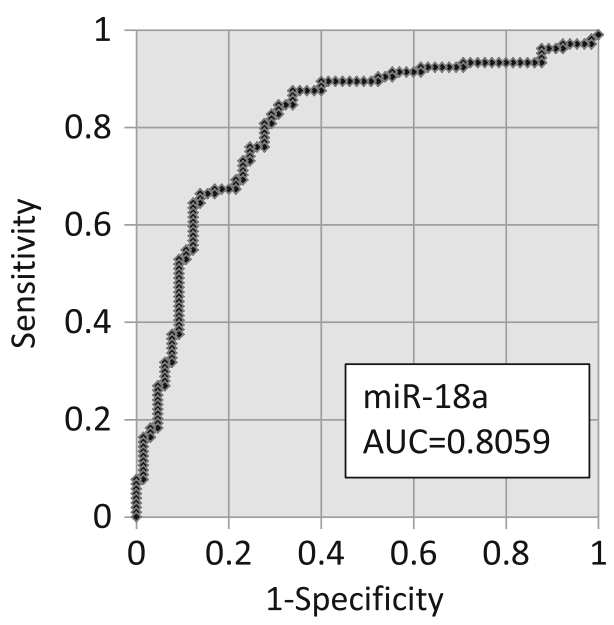

median, respectively. The upper and lower horizontal bars denote the 90th and 10th percentiles. b Receiver-operating characteristic (ROC) curve analysis in the plasma miR-18a assay for detecting GC patients. The ROC analysis showed an area under curve (AUC) of 0.8059

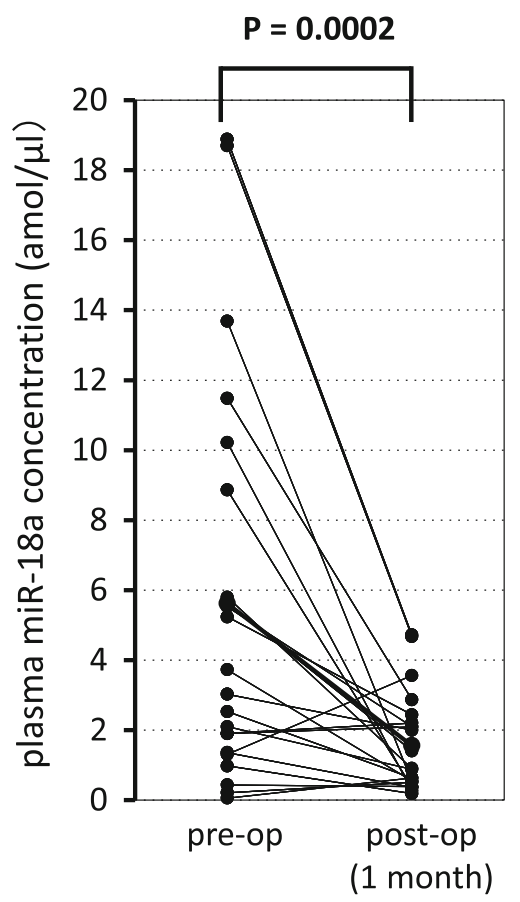

Fig. 3 Comparison of plasma miR-18a concentrations between paired pre- and postoperative samples from GC patients. The plasma miR-18a concentrations were significantly decreased in postoperative samples compared with the levels in preoperative samples $(P=0.0002$, Wilcoxon signed-rank test $)$

Evaluation of monitoring tumor dynamics using miR18a concentrations of cultured medium in miR-18a overexpressing GC cell lines

It has been reported that primary cancer cells could secrete cancer-specific miRNAs into surrounding environments, 
a

Time course of "Experiment A"

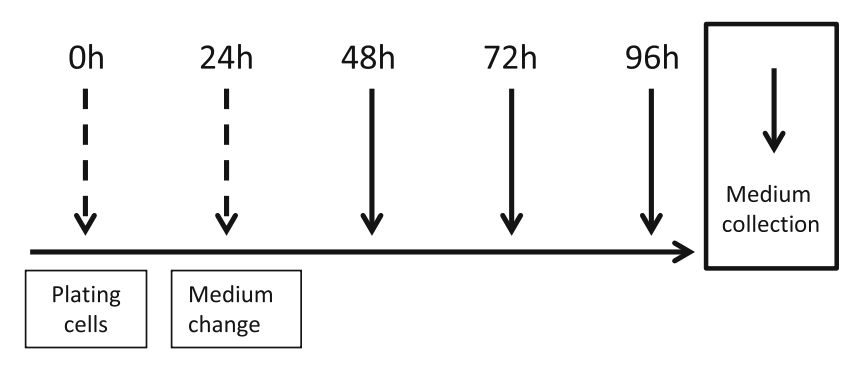

b

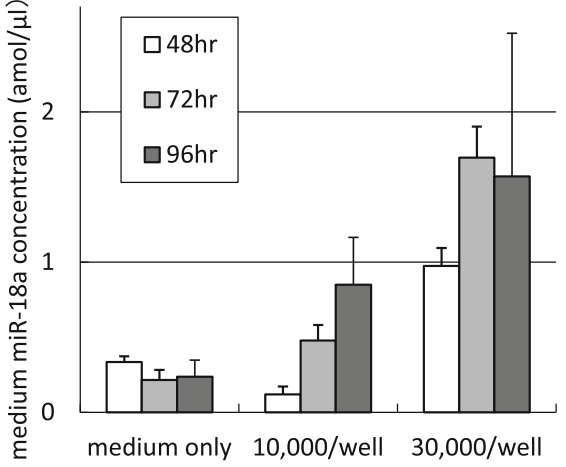

C

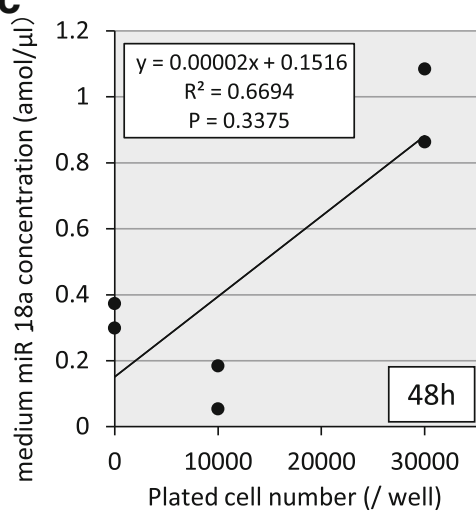

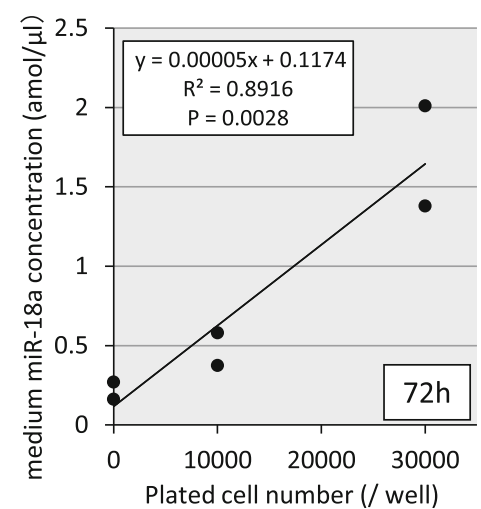

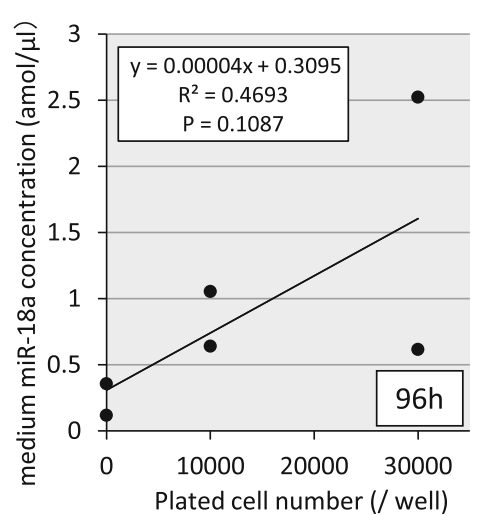

Fig. 4 Comparison of medium miR-18a concentration and plated GC cells. a The experimental design, in which medium was changed at $24 \mathrm{~h}$ after cell plating. b The concentration of miR-18a in cultured medium. No remarkable changes of medium miR-18a concentration were exhibited in non-cell plated samples; however, increased tendencies were confirmed in 10,000 and 30,000 cell-plated samples in both cell number- and time-course-dependent manners. c The correlation between medium miR-18a concentrations and plated cell numbers. A significant correlation was confirmed at $72 \mathrm{~h}$ $(P=0.0028$, Spearman's rank correlation coefficient $)$

96 h $(P=0.1087$; Fig. 4c $)$, respectively. While the medium was not changed, as expected, the high miR-18a concentrations at $0 \mathrm{~h}$ decreased toward $48 \mathrm{~h}$ and tended to increase again at $72 \mathrm{~h}$ (Supplementary Figure S2). Consequently, these results suggest that miRNAs might be released from cancer cells into the surrounding environment, implying that the plasma miR-18a might originate from primary GC cells and its plasma expression level could reflect tumor dynamics of cancer patients with GC.

Correlation between plasma miR-18a concentrations and peripheral blood cells

Recent reports suggested that some circulating miRNAs could have originated from peripheral blood cells [42, 43]. Therefore, we examined the correlation between plasma miR-18a concentrations and laboratory data of peripheral blood cells in all $104 \mathrm{GC}$ patients. As a result, there was no significant correlation between miR-18a levels and any type of blood cells (Supplementary Figure S3). These findings indicate that plasma miR-18a in GC patients may not be derived from peripheral blood cells. 


\section{Discussion}

Several factors seem to restrict diagnostic and therapeutic strategy for treatment of GC and, consequently, to incur the insufficient survival rate: (1) a lack of satisfactory diagnostic assays for early detection of GC; (2) an absence of valuable prognostic indicators; (3) the insufficient effectiveness of current treatments including surgery and chemotherapy for GC patients with advanced stages; (4) poorly understood mechanisms of tumor progression and resistance to treatments, and a consequent deficiency of targeted therapy. Therefore, the importance of developing useful diagnostic and monitoring tools should be emphasized to improve the clinical outcome of patients with GC.

Numerous genetic and epigenetic alterations contribute to oncogenesis and cancer progression. Among these alterations, miRNAs have been proven to regulate gene expressions by targeting mRNAs for translational repression or cleavage, and numerous studies have shown that aberrant miRNA expressions correlate with development and progression in various malignancies [7, 8, 44]. Therefore, miRNAs have recently been recognized as crucial contributory factors in carcinogenesis and can provide promising strategies as diagnostic biomarkers as well as therapeutic targets in cancers. Several studies have identified tumor-specific alterations of circulating nucleic acids in the blood of cancer patients and demonstrated their possibilities as useful biomarkers in screening and therapeutic management of disease $[45,46]$. Particularly, miRNAs have been shown to exist highly stably in plasma/ serum [10, 47], and accumulating reports have demonstrated the usefulness of circulating miRNAs as novel noninvasive biomarkers in various types of cancer, including our previous reports in GC [37], esophageal cancer [38] and pancreatic cancer [39].

The MiR-17-92 cluster was reported to possess potential oncogenic function $[17,18]$. In addition, recent reports have revealed the correlation between its upregulation and cell proliferation derived from either genome amplification or transcriptional activators such as MYC and E2Fs [1921], as well as the p53-mediated repression of this cluster under hypoxic conditions [22]. Also in GC, the overexpressions of the miR-17-92 cluster in primary tissues have been demonstrated [23-29]. Those findings prompted us to focus on this promising region, the miR-17-92 cluster, for this study. We took particular note of miR-18a according to the detailed evaluation of previous reports and hypothesized that plasma miR-18a would be a useful biomarker in GC.

To verify this hypothesis, first, we confirmed the higher miR-18a expressions in GC tissues and cell lines than in normal gastric tissues and fibroblasts (Fig. 1b, c). Then, we demonstrated the significantly higher plasma miR-18a levels in GC patients compared with controls, accompanying satisfactory specificity and sensitivity in the ROC curve analysis with a AUC of 0.8059 (Fig. 2a, b). Of particular note, the miR-18a concentration in plasma was markedly higher compared with other miRNAs that we previously investigated using the same methodology as for GC patients [37], suggesting that miR-18a is remarkably stable in plasma as a PCR-based biomarker and has potential usefulness for the clinical setting.

Next, we investigated whether plasma miR-18a concentrations could reflect tumor dynamics in GC by three different analyses. The first analysis involved the comparison of miR-18a concentrations in paired plasma samples obtained before and after curative tumor resection, which exhibited significantly reduction postoperatively (Fig. 3). The second analysis was the comparison between miR-18a expression in paired plasma and primary tumors. High levels of plasma miR-18a represented higher expressions in primary GC tissues in most cases analyzed ( 8 out of 11 cases, $77.7 \%$; data not shown). Some patients showed different patterns of miR-18a expression between plasma samples and primary tissues, similar to our previous reports [37-39]. The discrepancies remain to be clarified; however, one possible explanation of this finding is the heterogeneity of primary tumors. The third analysis involved determining whether the miR-18a level in culture medium could reflect the status of GC cell lines and might be released from tumor cells (Fig. 4; Supplementary Figure S2). We clearly demonstrated that the miR-18a levels in cultured medium have increased in both cell number- and time-course-dependent manners, suggesting that miRNA might be released from cancer cells into surrounding environments.

Concerning the miRNA release into blood from tumor cells, there have been some reports related to miRNA mediated intercellular communication. Skog et al. [48] reported that tumor-derived microvesicles that contained mRNA, miRNA and angiogenic proteins served as a means of delivering genetic information as well as proteins to recipient cells in the tumor environment. Kosaka et al. [14] also proved that miR-146a, a potent tumor-suppressive miRNA in prostate cancer, knocked down the target protein ROCK1 and inhibited cell proliferation in recipient cells. Moreover, their subsequent paper demonstrated that a variety of tumor-suppressive miRNAs were secreted by normal prostatic epithelial cells, and particularly miR-143 could inhibit cancer cell growth exclusively both in vitro and in vivo [49]. Although the miR-17-92 cluster was reported to have potential oncogenic roles in various cancers $[17,18]$, the abundance of the plasma miR-18a in GC patients and its detailed meanings remain unclear. These issues are currently under evaluation and will be reported in the near future. 
Other cautionary notes in plasma miRNA assay include the fact that circulating miRNAs could originate from peripheral blood cells of both cancer patients and normal individuals $[42,43]$. Therefore, we evaluated the correlation between plasma miR-18a concentrations and peripheral blood cells and confirmed no significant associations between plasma miR-18a concentrations and any type of peripheral blood cells (Supplementary Figure S3). This finding additionally implies that the plasma circulating miR-18a may not be derived from peripheral blood cells but GC cells and may, therefore, reflect tumor dynamics.

In conclusion, this study clearly demonstrated the usefulness of the circulating miR-18a for screening GC patients and monitoring tumor dynamics. Although the abundance and stability of plasma miR-18a indicate its great potential as a valuable biomarker in predicting the behavior of individual cancers and monitoring therapeutic responses, many issues should be addressed toward clinical application. Furthermore, it may be desirable to explore more sensitive molecules in the plasma miRNA assay. These issues are currently under evaluation in a large-scale analysis of the miR-18a assay, and an array-based study including a greater number of candidate miRNAs will be reported in the near future.

Conflict of interest The authors have no conflict of interest.

\section{References}

1. Jemal A, Bray F, Center MM, Ferlay J, Ward E, Forman D. Global cancer statistics. CA Cancer J Clin. 2011;61:69-90.

2. Hartgrink HH, Jansen EP, van Grieken NC, van de Velde CJ. Gastric cancer. Lancet. 2009;374:477-90.

3. Palanisamy N, Ateeq B, Kalyana-Sundaram S, Pflueger D, Ramnarayanan K, Shankar S, et al. Rearrangements of the RAF kinase pathway in prostate cancer, gastric cancer and melanoma. Nat Med. 2010;16:793-8.

4. Asaoka Y, Ikenoue T, Koike K. New targeted therapies for gastric cancer. Expert Opin Investig Drugs. 2011;20:595-604.

5. Lamerz R. Role of tumour markers, cytogenetics. Ann Oncol. 1999;10(Suppl 4):145-9.

6. Ghildiyal M, Zamore PD. Small silencing RNAs: an expanding universe. Nat Rev Genet. 2009;10:94-108.

7. Lu J, Getz G, Miska EA, Alvarez-Saavedra E, Lamb J, Peck D, et al. MicroRNA expression profiles classify human cancers. Nature. 2005;435:834-8.

8. Croce CM. Causes and consequences of microRNA dysregulation in cancer. Nat Rev Genet. 2009;10:704-14.

9. Ichikawa D, Komatsu S, Konishi H, Otsuji E. Circulating microRNA in digestive tract cancers. Gastroenterology. 2012;142(1074-8):e1.

10. Mitchell PS, Parkin RK, Kroh EM, Fritz BR, Wyman SK, Pogosova-Agadjanyan EL, et al. Circulating microRNAs as stable blood-based markers for cancer detection. Proc Natl Acad Sci. 2008;105:10513-8.

11. Arroyo JD, Chevillet JR, Kroh EM, Ruf IK, Pritchard CC, Gibson $\mathrm{DF}$, et al. Argonaute 2 complexes carry a population of circulating
microRNAs independent of vesicles in human plasma. Proc Natl Acad Sci USA. 2011;108:5003-8.

12. Vickers KC, Palmisano BT, Shoucri BM, Shamburek RD, Remaley AT. MicroRNAs are transported in plasma and delivered to recipient cells by high-density lipoproteins. Nat Cell Biol. 2011;13:423-33.

13. Turchinovich A, Weiz L, Langheinz A, Burwinkel B. Characterization of extracellular circulating microRNA. Nucleic Acids Res. 2011;39:7223-33.

14. Kosaka N, Iguchi H, Yoshioka Y, Takeshita F, Matsuki Y, Ochiya T. Secretory mechanisms and intercellular transfer of microRNAs in living cells. J Biol Chem. 2010;285:17442-52.

15. Zhang Y, Liu D, Chen X, Li J, Li L, Bian Z, et al. Secreted monocytic miR-150 enhances targeted endothelial cell migration. Mol Cell. 2010;39:133-44.

16. Zernecke A, Bidzhekov K, Noels H, Shagdarsuren E, Gan L, Denecke B, et al. Delivery of microRNA- 126 by apoptotic bodies induces CXCL12-dependent vascular protection. Sci Signal. 2009;2:ra81.

17. Dews M, Homayouni A, Yu D, Murphy D, Sevignani C, Wentzel E, et al. Augmentation of tumor angiogenesis by a Myc-activated microRNA cluster. Nat Genet. 2006;38:1060-5.

18. Hayashita Y. A polycistronic microRNA cluster, miR-17-92, is overexpressed in human lung cancers and enhances cell proliferation. Cancer Res. 2005;65:9628-32.

19. He L, Thomson JM, Hemann MT, Hernando-Monge E, Mu D, Goodson S, et al. A microRNA polycistron as a potential human oncogene. Nature. 2005;435:828-33.

20. Woods K, Thomson JM, Hammond SM. Direct regulation of an oncogenic micro-RNA cluster by E2F transcription factors. J Biol Chem. 2007;282:2130-4.

21. O'Donnell KA, Wentzel EA, Zeller KI, Dang CV, Mendell JT. c-Myc-regulated microRNAs modulate E2F1 expression. Nature. 2005;435:839-43.

22. Yan H-L, Xue G, Mei Q, Wang Y-Z, Ding F-X, Liu M-F, et al. Repression of the miR-17-92 cluster by $\mathrm{p} 53$ has an important function in hypoxia-induced apoptosis. EMBO J. 2009;28:2719-32.

23. Guo J, Miao Y, Xiao B, Huan R, Jiang Z, Meng D, et al. Differential expression of microRNA species in human gastric cancer versus non-tumorous tissues. J Gastroenterol Hepatol. 2009;24:652-7.

24. Kim YK, Yu J, Han TS, Park SY, Namkoong B, Kim DH, et al. Functional links between clustered microRNAs: suppression of cell-cycle inhibitors by microRNA clusters in gastric cancer. Nucleic Acids Res. 2009;37:1672-81.

25. Yao Y, Suo AL, Li ZF, Liu LY, Tian T, Ni L, et al. MicroRNA profiling of human gastric cancer. Mol Med Report. 2009;2:963-70.

26. Tsukamoto Y, Nakada C, Noguchi T, Tanigawa M, Nguyen LT, Uchida $\mathrm{T}$, et al. MicroRNA-375 Is downregulated in gastric carcinomas and regulates cell survival by targeting PDK1 and 14-3-3. Cancer Res. 2010;70:2339-49.

27. Ueda T, Volinia S, Okumura H, Shimizu M, Taccioli C, Rossi S, et al. Relation between microRNA expression and progression and prognosis of gastric cancer: a microRNA expression analysis. Lancet Oncol. 2010;11:136-46.

28. Jin Z, Selaru FM, Cheng Y, Kan T, Agarwal R, Mori Y, et al. MicroRNA-192 and -215 are upregulated in human gastric cancer in vivo and suppress ALCAM expression in vitro. Oncogene. 2011;30:1577-85.

29. Oh HK, Tan ALK, Das K, Ooi CH, Deng NT, Tan IB, et al. Genomic loss of miR-486 regulates tumor progression and the OLFM4 antiapoptotic factor in gastric cancer. Clin Cancer Res. 2011;17:2657-67.

30. Alencar AJ, Malumbres R, Kozloski GA, Advani R, Talreja N, Chinichian $\mathrm{S}$, et al. MicroRNAs are independent predictors of 
outcome in diffuse large B-cell lymphoma patients treated with R-CHOP. Clin Cancer Res. 2011;17:4125-35.

31. Ayala de la Pena F, Kanasaki K, Kanasaki M, Tangirala N, Maeda G, Kalluri R. Loss of p53 and acquisition of angiogenic microRNA profile are insufficient to facilitate progression of bladder urothelial carcinoma in situ to invasive carcinoma. J Biol Chem. 2011;286:20778-87.

32. Leivonen SK, Makela R, Ostling P, Kohonen P, Haapa-Paananen $\mathrm{S}$, Kleivi K, et al. Protein lysate microarray analysis to identify microRNAs regulating estrogen receptor signaling in breast cancer cell lines. Oncogene. 2009;28:3926-36.

33. Liu WH, Yeh SH, Lu CC, Yu SL, Chen HY, Lin CY, et al. MicroRNA-18a prevents estrogen receptor-alpha expression, promoting proliferation of hepatocellular carcinoma cells. Gastroenterology. 2009;136:683-93.

34. Castellano L, Giamas G, Jacob J, Coombes RC, Lucchesi W, Thiruchelvam $\mathrm{P}$, et al. The estrogen receptor- -induced microRNA signature regulates itself and its transcriptional response. Proc Natl Acad Sci. 2009;106:15732-7.

35. Luo Z, Dai Y, Zhang L, Jiang C, Li Z, Yang J, et al. miR-18a promotes malignant progression by impairing microRNA biogenesis in nasopharyngeal carcinoma. Carcinogenesis. 2013;34: 415-25.

36. Sobin L, Gospodarowicz MK, Wittekind C, editors. International Union against cancer TNM classification of malignant tumours, 7th ed. Oxford: Wiley-Blackwell; 2009.

37. Tsujiura M, Ichikawa D, Komatsu S, Shiozaki A, Takeshita H, Kosuga $\mathrm{T}$, et al. Circulating microRNAs in plasma of patients with gastric cancers. Br J Cancer. 2010;102:1174-9.

38. Komatsu S, Ichikawa D, Takeshita H, Tsujiura M, Morimura R, Nagata $\mathrm{H}$, et al. Circulating microRNAs in plasma of patients with oesophageal squamous cell carcinoma. $\mathrm{Br} \mathrm{J}$ Cancer. 2011;105:104-11.

39. Morimura R, Komatsu S, Ichikawa D, Takeshita H, Tsujiura M, Nagata H, et al. Novel diagnostic value of circulating miR-18a in plasma of patients with pancreatic cancer. $\mathrm{Br} \mathrm{J}$ Cancer. 2011;105:1733-40.

40. Reid G, Kirschner MB, van Zandwijk N. Circulating microRNAs: association with disease and potential use as biomarkers. Crit Rev Oncol Hematol. 2011;80:193-208.

41. Livak KJ, Schmittgen TD. Analysis of relative gene expression data using real-time quantitative PCR and the 2(-Delta Delta C(T)) method. Methods. 2001;25:402-8.

42. Duttagupta R, Jiang R, Gollub J, Getts RC, Jones KW. Impact of cellular miRNAs on circulating miRNA biomarker signatures. PLoS One. 2011;6:e20769.

43. Pritchard CC, Kroh E, Wood B, Arroyo JD, Dougherty KJ, Miyaji MM, et al. Blood cell origin of circulating microRNAs: a cautionary note for cancer biomarker studies. Cancer Prev Res. 2011;5:492-7.

44. Calin GA, Croce CM. MicroRNA signatures in human cancers. Nat Rev Cancer. 2006;6:857-66.

45. Sidransky D. Nucleic acid-based methods for the detection of cancer. Science. 1997;278:1054-9.

46. Diehl F, Schmidt K, Choti MA, Romans K, Goodman S, Li M, et al. Circulating mutant DNA to assess tumor dynamics. Nat Med. 2008;14:985-90.

47. Chen X, Ba Y, Ma L, Cai X, Yin Y, Wang K, et al. Characterization of microRNAs in serum: a novel class of biomarkers for diagnosis of cancer and other diseases. Cell Res. 2008;18: 997-1006.

48. Skog J, Wurdinger T, van Rijn S, Meijer DH, Gainche L, SenaEsteves M, et al. Glioblastoma microvesicles transport RNA and proteins that promote tumour growth and provide diagnostic biomarkers. Nat Cell Biol. 2008;10:1470-6.

49. Kosaka N, Iguchi H, Yoshioka Y, Hagiwara K, Takeshita F, Ochiya T. Competitive interactions of cancer cells and normal cells via secretory microRNAs. J Biol Chem. 2012;287: 1397-405. 